\title{
The effect of limestone powder, fly ash and silica fume on the properties of self-compacting repair mortars
}

\author{
SELÇUK TÜRKEL* and YIĞIT ALTUNTAŞ \\ Civil Engineering Department, Dokuz Eylül University, 35160, Turkey \\ e-mail: selcuk.turkel@deu.edu.tr (S.Türkel)
}

MS received 21 November 2007; revised 7 April 2008

\begin{abstract}
Self-compacting repair mortars (SCRM) are preferred for the rehabilitation and repair of reinforced concrete structures especially at narrow mould systems. Self compactability and stability are susceptible to ternary effects of chemical and mineral admixture type and their content. In this study, the effect of limestone powder (LP) on the properties of SCRM has been compared with other mineral additives (silica fume (SF) and fly ash (FA) and their combinations) effects. Fresh properties, flexural and compressive strengths and water absorption properties of mortars were determined. The use of SF in mortars significantly increased the dosage of superplasticiser (SP). At the same constant SP dosage (0.8\%) and mineral additives content (30\%), LP can better improve the workability than that of control and FA mixtures by $19 \%$ and $27 \%$. However, the results of this study suggest that certain FA, SF and LP combinations can improve the workability of SCRMs, more than FA, SF and LP alone. LP can have a positive influence on the mechanical performance at early strength development while SF improved aggregate-matrix bond resulting from the formation of a less porous transition zone in mortar. SF can better reducing effect on total water absorption while FA and LP will not have the same effect, at 28 days.
\end{abstract}

Keywords. Self-compacting repair mortar; limestone powder; workability; strength; water absorption.

\section{Introduction}

Self-compacting repair mortars (SCRMs), as relatively new technology products are especially preferred for the rehabilitation and repair of reinforced concrete structures (Courard et al 2002). The self-compactability of repair mortars may bring considerable advantages at narrow mould systems (Khayat \& Mourin 2002). With the development of new generation high range water reducer admixture, to obtain high filling rates is possible even for complex molding systems (O'Flaherty \& Mangat 1999). In structural repairs, the repair material should provide the targeted mechanical properties (Poston et al 2001). It is possible to improve the

*For correspondence 
mechanical properties of mortars by using chemical, mineral, polymer and fibre additives. For instance, producing of SCRMs with the use of chemical additives, decreasing shrinkage and permeability and using mineral additives increased compressive strength.

As it is well known, there are a wide range of cementitious mortars based on cement and components similar to those of concrete. The composition of mortars could sometime consist of more than one type of cement (i.e. special cement, like ultra-fine alumina cement) together with additions (i.e. silica fume, slag or fly ash), aggregates (normal, lightweight and special types, fillers), admixtures such as superplasticiser (SP), air entrainers and accelerators, polymer additives and fine polymer fibres (Gudmudsson \& Olafsson 1996; Lagerblad \& Utkin 1993; Marusin \& Shotwell 1995). The use of industrial by-products, such as FA, SF, offers a low-priced solution to the environmental problem of depositing industrial waste (Kasselouri \& Parissakis 1977).

The viscosity of cement-based material can be improved by decreasing the water/ cementitious material ratio $(\mathrm{w} / \mathrm{cm})$ or using a viscosity-enhancing agent. It can also be improved by increasing the cohesiveness of the paste through the addition of filler, such as limestone (Ozawa et al 1995, Khayat 1999). However, excessive addition of fine particles can result in a considerable increase in the specific surface area of the powder, which results in an increase of water demand to achieve a given consistency. On the other hand, for a fixed water content, high powder volume increases interparticle friction due to solid-solid contact. This may affect the ability of the mixture to deform under its own weight and pass through obstacles (Nawa et al 1998).

The use of limestone powder can enhance many aspects of cement-based systems through physical or chemical effects. Some physical effects are associated with the small size of limestone particles, which can enhance the packing density of powder and reduce the interstitial void, thus decreasing entrapped water in the system. For example, the use of a continuously graded skeleton of powder is reported to reduce the required powder volume to ensure adequate deformability for concrete (Fujiwara et al 1996). Chemical factors include the effect of limestone filler in supplying ions into the phase solution, thus modifying the kinetics of hydration and the morphology of hydration products (Daimon \& Sakai 1998). Partial replacement of cement by an equal volume of limestone powder with a specific surface area ranging between 500 and $1000 \mathrm{~m}^{2} / \mathrm{kg}$ resulted in an enhancement in fluidity and a reduction of the yield stress of highly flowable mortar (Yahia et al 1999). Other investigations have shown that partial replacement of cement by an equal volume of limestone powder varying from $5 \%$ to $20 \%$ resulted in an enhancement of the fluidity of high-performance concrete having a W/C ratio ranging between 0.35 and 0.41 (Nehdi et al 1998). This improvement may be due to the increase in $\mathrm{W} / \mathrm{C}$ or in paste volume. Indeed, for a given water content, partial replacement of cement by an equal volume of a filler results in an increase in W/C. On the other hand, partial replacement of cement by an equal mass of limestone powder results in an increase of powder content, i.e. an increase in paste volume. For example, the partial substitution of cement by $40 \%$ (by mass of limestone filler) having a specific gravity of 2.7 yields to a $17 \%$ increase in powder volume.

The durability of a concrete repair can depend on many factors. Those most often considered are cement reactivity with environment, low permeability, diffusion coefficient of species such as sulfate ions and compressive strength. The water absorption is also very important factor effecting durability such as freezing and thawing. The use of mineral additives may provide a way of improving the durability of SCRM depending on the type and amount of mineral additive used. In addition, in the absence of self-compactability the success of mortars depends on the compaction degree supplied at application site. 
For improving strength and durability properties; limestone powders produce a more compact structure by pore-filling effect. In the case of SF and FA, it also reacts with cement by binding $\mathrm{Ca}(\mathrm{OH})_{2}$ with free silica by a pozzolanic reaction forming a non-soluble CSH structure (O'Flaherty \& Mangat 1999).

The main objective of the present study is to investigate a suitable combination of LP, FA and SF that would improve the properties of the SCRMs more than when these materials would be used separately.

\section{Experimental study}

\subsection{Materials}

An ordinary portland cement (CEM-I $42.5 \mathrm{~N}$ ) was used in the experimental program. Cements in conformity with Turkish-European Standards TS EN 197-1 (2002), were manufactured by Cimentas Cement Plant, Izmir, Turkey. The compressive strengths of cement at 2, 7 and 28 days are 25.4, 41.2 and 50.6 MPa respectively. Silica fume (SF) procured from Scancem Chemicals, Norway and C type lignite fly ash (FA) procured from Soma B power plant, Turkey. The limestone powder (LP) used in this study was from Öztüre Muğla factory. The chemical analysis and physical properties of these materials are presented in table 1. A high-range water reducer admixture based on poly-carboxylate polymer, Smartflow (HS100) complying with the ASTM C 494 (F type) (2002) specification was used in mortar mixes. The superplasticizer (SP) was produced by Konsan Science and Technology Production Corporation, Izmir, Turkey. The solid content, $\mathrm{pH}$ and specific gravity of admixture were 35.7 percent, 6.5 and 1.11 , respectively. The maximum diameter of the natural sand used in mortar mixes was $4 \mathrm{~mm}$. The water used in the experiments was tap water.

\subsection{Preparation of specimens and test methods}

Twelve SCM mixtures one is plain and others containing different types of mineral additives were prepared. The mixture proportion of mineral admixture composition, SP dosages and

Table 1. The chemical composition and some of the physical properties of cement, FA, LP and SF.

\begin{tabular}{|c|c|c|c|c|}
\hline Basic compounds (\%) & Cement & FA & LP & SF \\
\hline $\mathrm{CaO}$ & $63 \cdot 70$ & $26 \cdot 96$ & $52 \cdot 35$ & $0 \cdot 49$ \\
\hline $\mathrm{SiO}_{2}$ & 19.68 & $42 \cdot 14$ & 0.45 & $92 \cdot 26$ \\
\hline $\mathrm{Al}_{2} \mathrm{O}_{3}$ & $5 \cdot 75$ & $19 \cdot 38$ & $0 \cdot 33$ & $0 \cdot 89$ \\
\hline $\mathrm{Fe}_{2} \mathrm{O}_{3}$ & $3 \cdot 00$ & $4 \cdot 64$ & $0 \cdot 14$ & 1.97 \\
\hline $\mathrm{MgO}$ & $0 \cdot 90$ & 1.78 & 1.05 & $0 \cdot 96$ \\
\hline $\mathrm{Na}_{2} \mathrm{O}$ & $0 \cdot 20$ & - & $0 \cdot 06$ & $0 \cdot 42$ \\
\hline $\mathrm{K}_{2} \mathrm{O}$ & $0 \cdot 83$ & $1 \cdot 13$ & $0 \cdot 02$ & $1 \cdot 31$ \\
\hline $\mathrm{SO}_{3}$ & $2 \cdot 78$ & $2 \cdot 43$ & - & $0 \cdot 33$ \\
\hline $\mathrm{Cl}$ & $0 \cdot 01$ & $0 \cdot 001$ & - & 0.09 \\
\hline Loss on ignition & $2 \cdot 84$ & $1 \cdot 34$ & $42 \cdot 50$ & $2 \cdot 05$ \\
\hline Free $\mathrm{CaO}$ & $1 \cdot 55$ & $4 \cdot 34$ & - & - \\
\hline Insoluble residue & $0 \cdot 70$ & - & $0 \cdot 20$ & - \\
\hline Specific surface $\left(\mathrm{m}^{2} / \mathrm{kg}\right)$ & 340 & 290 & 538 & 22130 \\
\hline Specific gravity & $3 \cdot 14$ & $2 \cdot 20$ & $2 \cdot 65$ & $2 \cdot 25$ \\
\hline
\end{tabular}


Table 2. FA, SF and LP proportions of SCRMs.

\begin{tabular}{llrrrr}
\hline & & \multicolumn{4}{c}{ Binder proportions (\%) } \\
\cline { 3 - 6 } $\begin{array}{l}\text { Mixture } \\
\text { Number }\end{array}$ & \multicolumn{1}{c}{$\begin{array}{c}\text { Mixture } \\
\text { Notation }\end{array}$} & Cement & SF & FA & LP \\
\hline M1 & Control & 100 & - & - & - \\
M2 & FA30 & 70 & - & 30 & - \\
M3 & LP30 & 70 & - & - & 30 \\
M4 & SF30 & 70 & 30 & - & - \\
M5 & FA25 LP5 & 70 & - & 25 & 5 \\
M6 & FA25 SF5 & 70 & 5 & 25 & - \\
M7 & FA20 LP10 & 70 & - & 20 & 10 \\
M8 & FA20 LP5 SF5 & 70 & 5 & 20 & 5 \\
M9 & FA20 SF10 & 70 & 10 & 20 & - \\
M10 & FA15 LP10 SF5 & 70 & 5 & 15 & 10 \\
M11 & FA15 LP5 SF10 & 70 & 10 & 15 & 5 \\
M12 & FA10 LP10 SF10 & 70 & 10 & 10 & 10 \\
\hline
\end{tabular}

SCM mixture designs are based on a previous study (Altuntaş 2005). 30\% of cement by weight was replaced by SF, FA and LP and their combination in different proportions. In all mixtures the water/binder and sand/binder ratios were kept constant to 0.50 and 2.25 respectively. Hobart mixer was used for the mixing of mortars. The amount of mortar combination is adjusted to $1.2 \mathrm{~L}$ per batch. The mixture proportions of 12 different mixes including control mixture are presented in table 2 .

Different proportions of SP were used in all mixtures (figure 1). SP proportions are by total binder weight. It was targeted to obtain self-compacting properties in all mixtures. The spread values have been measured using mini-slump flow test in conformity with EFNARC (2005) standards. Typical dimensions of spread cone are shown in figure 2 . In this test, the

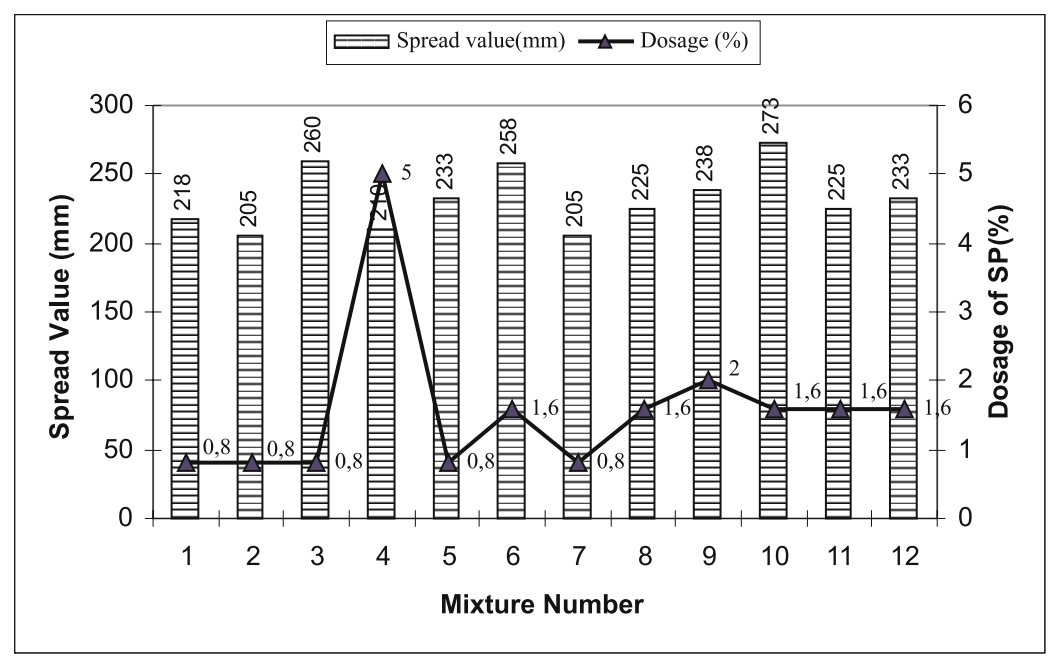

Figure 1. SP dosage and spread value. 


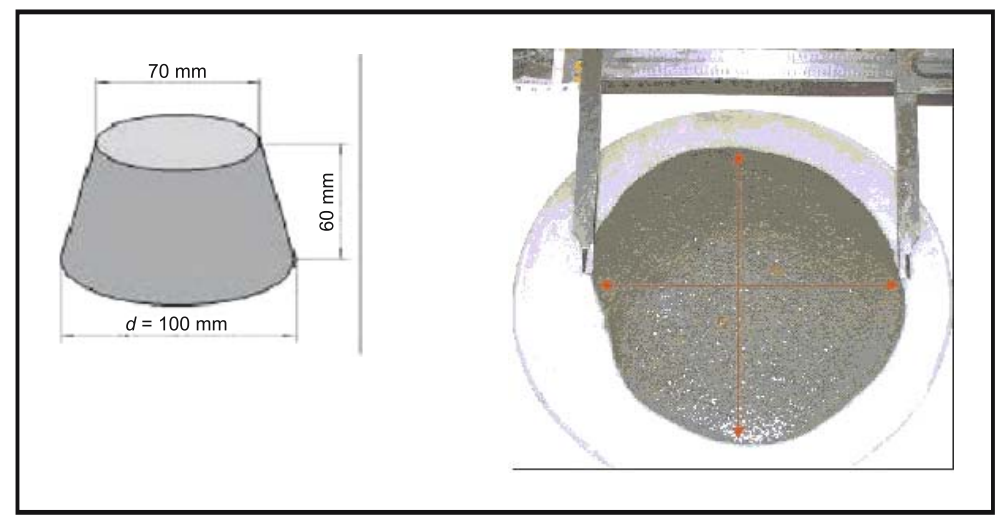

Figure 2. Typical dimensions of spread cone.

truncated cone mold is placed on a metal plate, filled with mortar and lifted vertically. The spread diameter of the mortar is measured in two perpendicular directions, and the mean is taken (Domone \& Jin 1999). The initial diameter of the cone is $100 \mathrm{~mm} .200 \mathrm{~mm}$ spread value was chosen as lower limit for all mixtures. Segregation was observed in mortar mixtures that had spread values greater than $280 \mathrm{~mm}$. Therefore, $280 \mathrm{~mm}$ was chosen as upper limit. The stability of mixes was controlled by visual inspection.

After the completion of fresh state tests, the mortar mixture is poured into prismatic molds with $40 \times 40 \times 160 \mathrm{~mm}$ for mechanical strengths and the total and capillary water absorption test without any compaction or vibration. Specimens were demolded after $24 \pm 2$ hours and kept in lime saturated water until the testing day. Flexural and compressive strength tests were performed in conformity with ASTM C348 (2002) and ASTM C349 (2002) standard at 2, 7 and 28 days after casting. Test results for flexural strength obtained from the average of three specimens and compressive strength obtained from the average of six broken pieces of specimens for each age. Total and capillary water absorption tests were performed at 28 days on three specimens for every mixture. Before testing, test prisms were dried in the oven at $105^{\circ} \mathrm{C}$ to constant mass. The water absorption by capillarity of SCRMs was performed according to the TS 4045 (1984). The specimens were kept totally in water while in capillary water absorption test $40 \times 40 \mathrm{~mm}$ base area of specimens was sunk in water at a depth of $1 \mathrm{~mm}$. The increases in mass of specimens were measured.

\section{Results and discussions}

\subsection{Fresh properties}

The spread value of SCRM mixtures was in the range of 205 to $273 \mathrm{~mm}$ (figure 1). Due to the very different rheological properties of mortar mixtures, it was not possible to compare the spread values by using a constant proportion of SP in all mixtures. A constant dosage of SP made one mixture not spread at all while making another mixture segregate. For this reason, a coefficient showing the spread value per unit SP dosage (1\% by binder weight) was calculated and the effects of additives on workability of mortar were compared by this way. The dosages of SP used in mineral modified mortars, spread values and the calculated spread value/per unit SP dosage proportions $(\mathrm{mm} / \%)$ are presented in figure 3. As expected, the use 


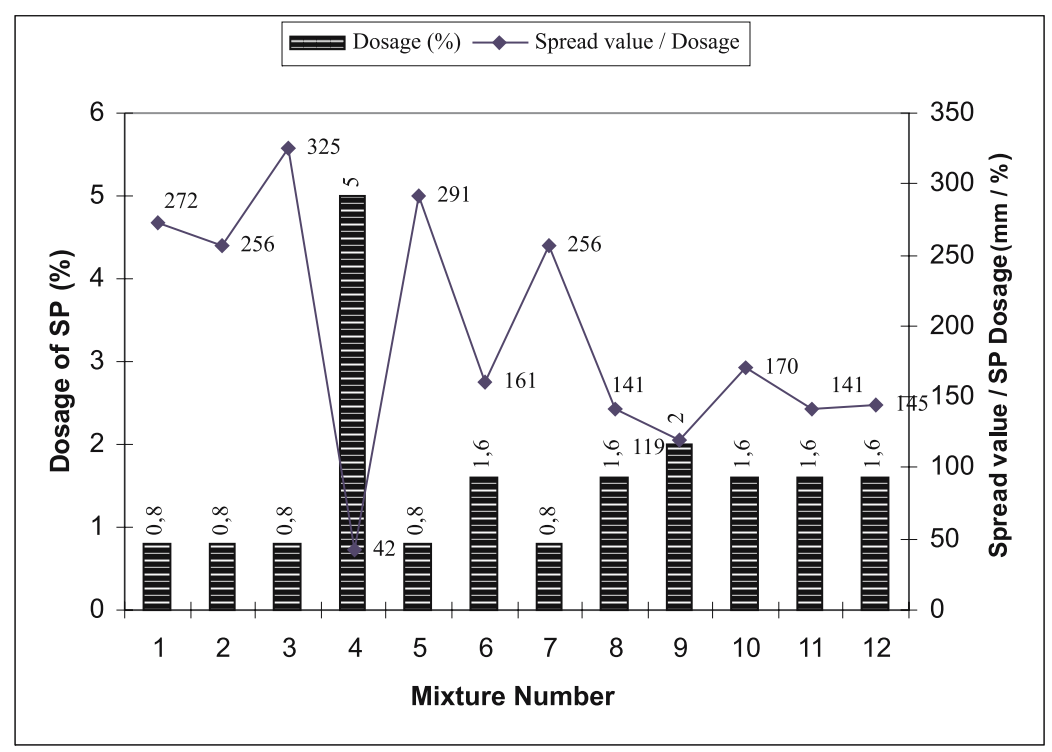

Figure 3. Spread value per unit SP dosage.

of SF in SCRMs significantly increased the dosage of SP because of its extremely high surface area for the constant water/binder ratio of 0.5 . The dosage of SP was $0.8 \%$ for $30 \%$ FA and LP (M2 and M3) replacement while 30\% SF (M4) replacement required 5\% SP. In spite of M4 has required higher dosage of SP; the spread value has become approximately as control mixture. Generally spread value decreased with mixtures contained of SF in SCRMs at the same SP dosages of $1.6 \%$ except FA20 SF10 combinations (M9). The results also show that $0.8 \%$ dosage of SP seems to be insensitive to the combination in different proportions of FA and LP mixtures (M5 (FA25 LP5) and M7 (FA20 LP10)). It can be seen that from figure 3, the lowest spread value/per unit SP dosage proportions were obtained for M4 (30\% SF) mixture. This result shows that $30 \%$ SF is not appropriate replaced in SCRMs for savings in cost.

In literature, it is expressed that LP is usually used for improving the workability and reducing the bleeding of mortar (Erdoğan 1997). It should also be noted that LP provides cohesiveness and plasticity of a mortar. At the same constant SP dosage of $0.8 \%$ the highest spread value was obtained for the LP30 (M3). This value is higher than that of control (M1) and 30\% FA (M2) mixtures by $19 \%$ and $27 \%$ at the same dosage respectively. The reason for this behaviour can be attributed to the fineness of limestone powders, since they were smaller than cement and FA particles (Felekoglu et al 2004). This suggests that the physical effect of the limestone powder on the properties of the fresh mortar depends on the W/cementitious material $(\mathrm{cm})$ and the addition percentages of limestone filler. In addition, the used limestone powder with a specific surface area $\left(538 \mathrm{~m}^{2} / \mathrm{kg}\right)$ ranging between 500 and $1000 \mathrm{~m}^{2} / \mathrm{kg}$ resulted in an enhancement in fluidity and a reduction of the yield stress of highly flowable mortar (Yahia et al 1999).

It was seen from the results (figure 1), mixtures containing 30\% FA influenced the spread that was lower than the control mixture by $6 \%$ at the same SP dosage. It can be said that 20 to $30 \%$ FA replacement was not positive effect on fresh properties of SCRMs in spite of it has normally beneficial effects on the workability. This can be attributed to its lower fineness (as seen from table 1). As it is known, coarser fly ashes have more irregular shapes 
and rougher surfaces when compared to finer fly ashes. In addition, ultra-fine powder can physically disperse cement flocks, thus freeing more paste to lubricate the aggregates and improving workability (Swamy 1986). For this reason, fly ash particles cause workability of fresh SCRMs to decrease.

Generally, the results obtained from the experimental studies the dosages of the SP used in SCRMs and also spread values depend on the mineral additive types due to their different fineness, particle shape and size. In addition to the dosages of the SP used in SCRMs, it should also be noted that chemical composition of the plasticizer is affected on the fresh properties. For targeted spread value, the dosages of SP used in mineral modified mortars changed with the mineral additives types and their combination in different proportions. The replacement of cement by mineral additives strongly influences the flow resistance; it may improve or worsen the workability. Test results indicate that the highest spread value had been obtained for mixture number of M10 (FA15 LP10 SF5). From this study suggest that certain FA, SF and LP combinations can improve the workability of SCRMs, more than FA, SF and LP alone.

\subsection{Mechanical properties}

The 2, 7 and 28-days flexural and compressive strengths for the 12 SCRMs are presented in table 3.28-days flexural strength was in the range of $7 \cdot 1$ to $12 \cdot 2 \mathrm{MPa}$ and compressive strength 33.7 to $70 \cdot 3 \mathrm{MPa}$. The highest flexural strength at 28-days was obtained for M9 (FA20 SF10) and the highest compressive strength for M4 (SF30). While 30\% SF replacement level that led to maximum compressive strength, maximum flexural strength was obtained at $10 \% \mathrm{SF}$ incorporation of $20 \%$ FA. Mortar is, of course, a mixture of the paste and aggregate, and it is the interface between these that is of interest. For the flexural strength could be supposed that it is more sensitivity of the transition zone between aggregate and matrix. Especially, as the bending load on the mortar increases, cracking will start in this zone, and subsequently propagate in to the hardened cement paste (hcp) until crack paths are formed through the mortar. The increase in strength in systems of mortars containing pozzolanic materials play an important role in improving the aggregate-paste bond through the densification of the

Table 3. Flexural and compressive strengths of SCRMs at different age.

\begin{tabular}{|c|c|c|c|c|c|c|}
\hline \multirow{2}{*}{$\begin{array}{l}\text { Mixture } \\
\text { number }\end{array}$} & \multicolumn{3}{|c|}{ Flexural strength (MPa) } & \multicolumn{3}{|c|}{ Compressive strength $(\mathrm{MPa})$} \\
\hline & $2 d$ & $7 \mathrm{~d}$ & $28 \mathrm{~d}$ & $2 d$ & $7 d$ & $28 \mathrm{~d}$ \\
\hline M1 & $7 \cdot 0$ & 8.8 & $10 \cdot 7$ & 33.4 & $46 \cdot 3$ & 59.4 \\
\hline M2 & $4 \cdot 6$ & $7 \cdot 1$ & 9.2 & $19 \cdot 1$ & $31 \cdot 1$ & $50 \cdot 5$ \\
\hline M3 & $4 \cdot 3$ & $5 \cdot 5$ & $7 \cdot 1$ & $16 \cdot 8$ & $27 \cdot 0$ & 33.7 \\
\hline M4 & $3 \cdot 8$ & $5 \cdot 5$ & $8 \cdot 3$ & $16 \cdot 3$ & $34 \cdot 5$ & $70 \cdot 3$ \\
\hline M5 & $4 \cdot 3$ & $6 \cdot 3$ & 9.8 & $18 \cdot 9$ & $30 \cdot 6$ & 47.7 \\
\hline M6 & $3 \cdot 9$ & $6 \cdot 3$ & 9.5 & $17 \cdot 8$ & $36 \cdot 9$ & $55 \cdot 6$ \\
\hline M7 & $4 \cdot 0$ & $5 \cdot 9$ & 8.9 & $17 \cdot 4$ & 29.3 & $43 \cdot 4$ \\
\hline M8 & $3 \cdot 9$ & $6 \cdot 5$ & 8.8 & $18 \cdot 1$ & 31.8 & $51 \cdot 3$ \\
\hline M9 & 4.6 & $7 \cdot 5$ & $12 \cdot 2$ & $22 \cdot 0$ & $36 \cdot 1$ & $57 \cdot 2$ \\
\hline M10 & $4 \cdot 3$ & 6.4 & $11 \cdot 2$ & $20 \cdot 5$ & $31 \cdot 2$ & $46 \cdot 8$ \\
\hline M11 & $4 \cdot 1$ & 6.4 & $11 \cdot 1$ & 19.7 & 32.7 & $51 \cdot 0$ \\
\hline M12 & 4.4 & $6 \cdot 1$ & $10 \cdot 5$ & 19.4 & $33 \cdot 1$ & 49.4 \\
\hline
\end{tabular}




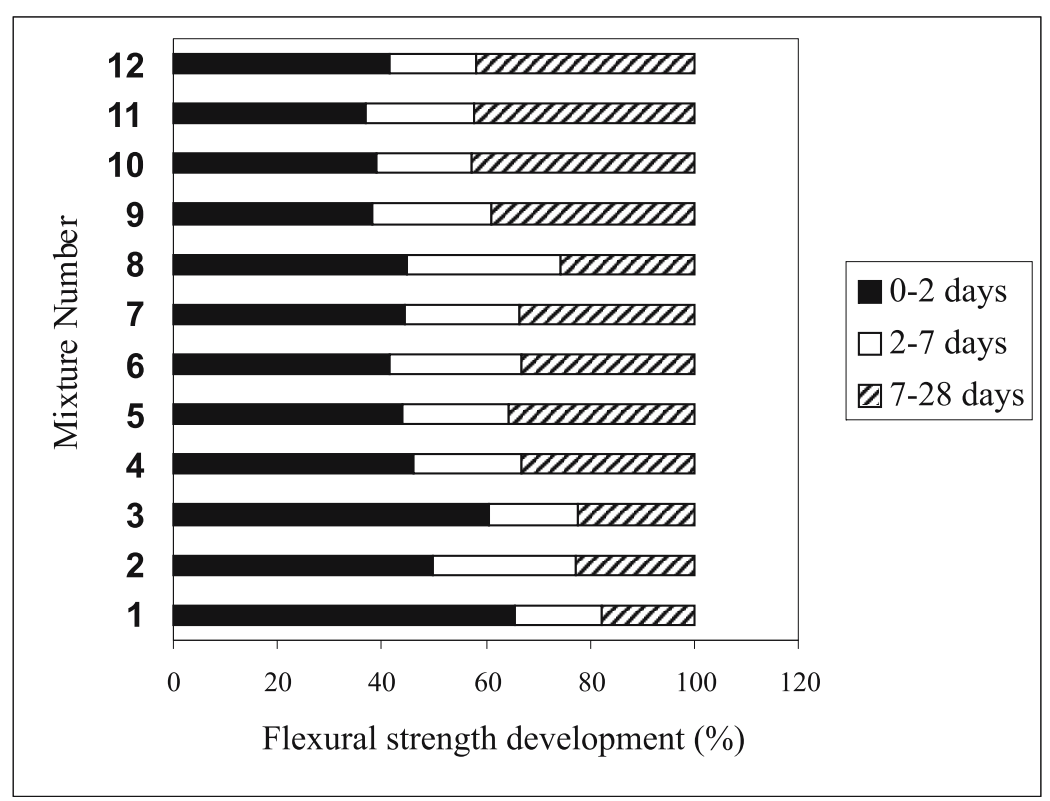

Figure 4. Flexural strength development ratios of SCRMs in different periods.

transition zone and formation of more calcium silicate hydrates (Shannag 2000). SF has higher fineness (as seen from table 1) and pozzolanic activity than the FA and LP. Thus, mixture contained of SF ensuring a better contribution to achieve adequate interfaced to the compressive and flexural strength. In this study, the use of FA and LP in SCRM that they have worsening effect on the interfaced due to the lower fineness and pozzolanic activity. Thus they have reducing effect of the mortar strength.

In literature, LP was described neither cementitious nor pozzolanic materials. Therefore, it is accepted that LP contributes little to the strength of mortar (Erdoğan 1997). As expected, the lowest flexural and compressive strength at 28-days was obtained for $30 \%$ of cement by weight was replaced by LP (M3). This result shows that LP appropriate to improve deformability, but it is not completely effective on mechanical properties. However, includes substitutions of cement with lowest LP (5 to 10\%) employed with other additives mainly to positive effect on the mechanical properties (table 2).

Control mixture has the second and fourth highest compressive and flexural strength respectively. This result shows that the SCRMs mechanical strength seems to be sensitive to the combination in different proportions of FA, SF and LP.

Generally, it may be mentioned here that the use of mineral additives combination in different proportions has been provided more flexural strength than the use of only one.

Strength development ratios of SCRMs in different periods for flexural and compressive strengths are indicated in figure 4 and figure 5 respectively. In figure 4 and figure 5 , the ratios for each SCMs are by its own flexural and compressive strength at 28 days. It can be seen from the figures, all the mixtures between 0 and 2 days have higher strength development ratios than 2-7 and 7-28 strength development ratios. All the mixtures showed that lower strength development between 2 and 7 days. It can be mentioned here that all mixtures have their own strength gain at early age of 2 days. At 2-day strengths, the mixes containing $30 \%$ limestone fillers showed higher compressive strength values when compared with FA and SF. However, 


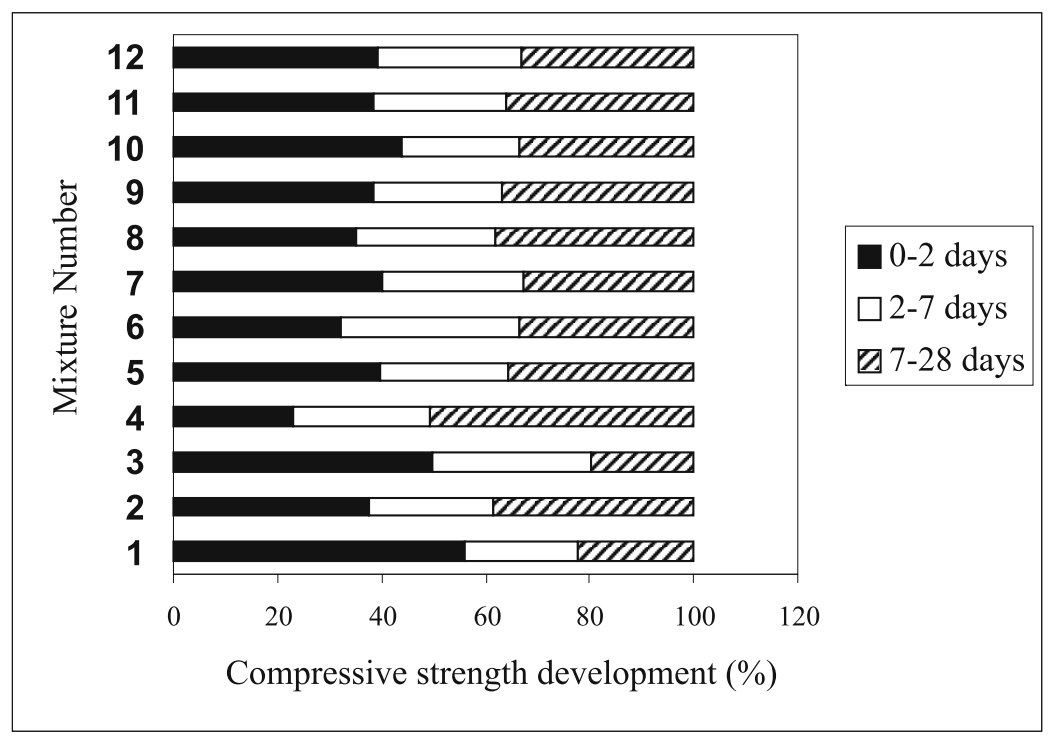

Figure 5. Compressive strength development ratios of SCRMs in different periods.

the highest strength development at 2 days was control mixture. The increase in compressive strength can be explained with pore-filling effect of fine-grounded limestone powder and also provided suitable nucleus for hydration and by this way catalysing the hydration (Gürol 1999). Additionally, limestone fillers reacted with $C_{3} \mathrm{~A}$ phase of cement and supplied the formation of monocarboaluminate that partially takes part of ettringite; thus, increase at early strength values (Türker et al 2004). However, it seems that no additional hydration reactions take place to enhance the long-term strength of pastes incorporating limestone fillers. This situation was caused by the slow pozzolanic reaction between the cement and fly ash that was well suited with the literature (Villain et al 1999). It should also be noted that the use of polycarboxylate-based SP at high dosages may also lengthen the setting times and negatively affect the early compressive strength of mixes incorporating fly ash (Felekoglu et al 2004).

It can be seen from figure 6 that the flexural strength to compressive strength ratio was about 0.20 independent of mineral additives types and specimens age except SF30. Flexural strength to compressive strength ratio is 0.12 for SF30 at 28-days.

The reasons for the different rates of strength gain with the three different mineral admixtures can be summarised as:

- the extremely fine particle, which act as nucleation sites for hydrate deposition, and very high active silica content of the SF;

- the FA is somewhat coarser so it is a little slower to react, but it contains a high active silica content and is therefore not far behind the SF mixes;

- the LP is neither cementitious nor pozzolanic materials which contributes little to the secondary reactions.

\subsection{Water absorption}

The total and capillary water absorption test results are shown in figure 7. SCRMs total and capillary water absorption at 24-hours was in the range of 2.11 to $5.63 \%$ and 0.62 to 


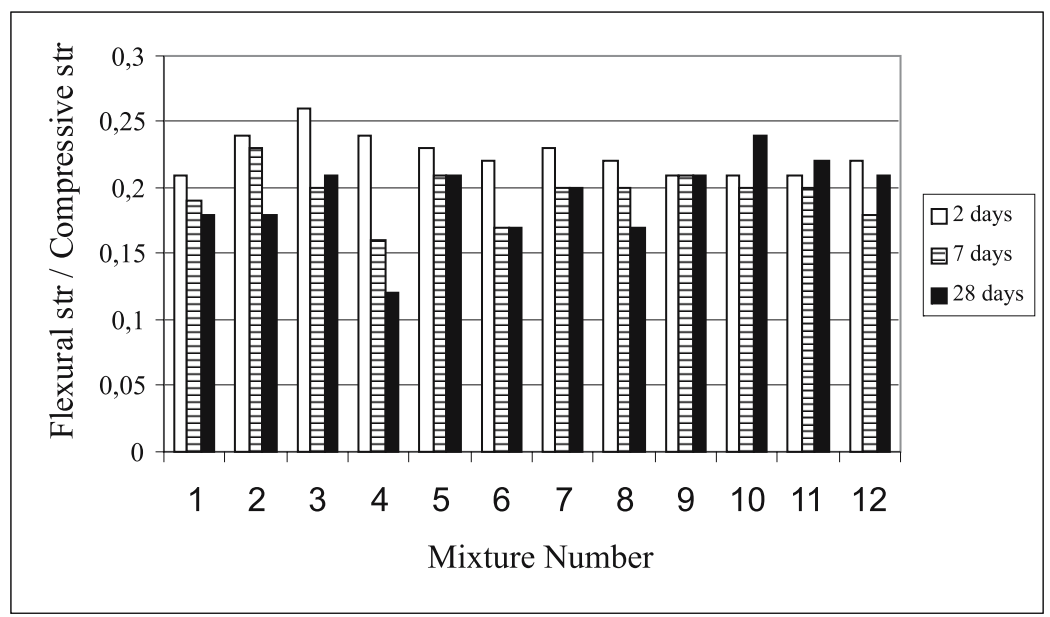

Figure 6. Flexural strength to compressive strength ratio at different age.

$1.17 \%$ respectively. The total water absorption values of the mixtures containing $30 \%$ mineral additives are greater than that of control mixture except 30\% SF. In all the SCRMs lowest total and capillary water absorption at 24-hours was obtained for M8 (FA20 LP5 SF5) and M1 (control) respectively. M8 has lower total water absorption by $34 \%$ than the control mixture (M1). Highest total and capillary water absorption at 24-hours was obtained for M7 (FA20 LP10). This mixture has higher by $77 \%$ and $89 \%$ total and capillary water absorption than the control mixture respectively. Generally it can be said that SF had reducing effect while FA and LP had not the same effect on total water absorption when used alone. This situation may bring out the opinion that LP and FA could not form to block capillary pores sufficiently

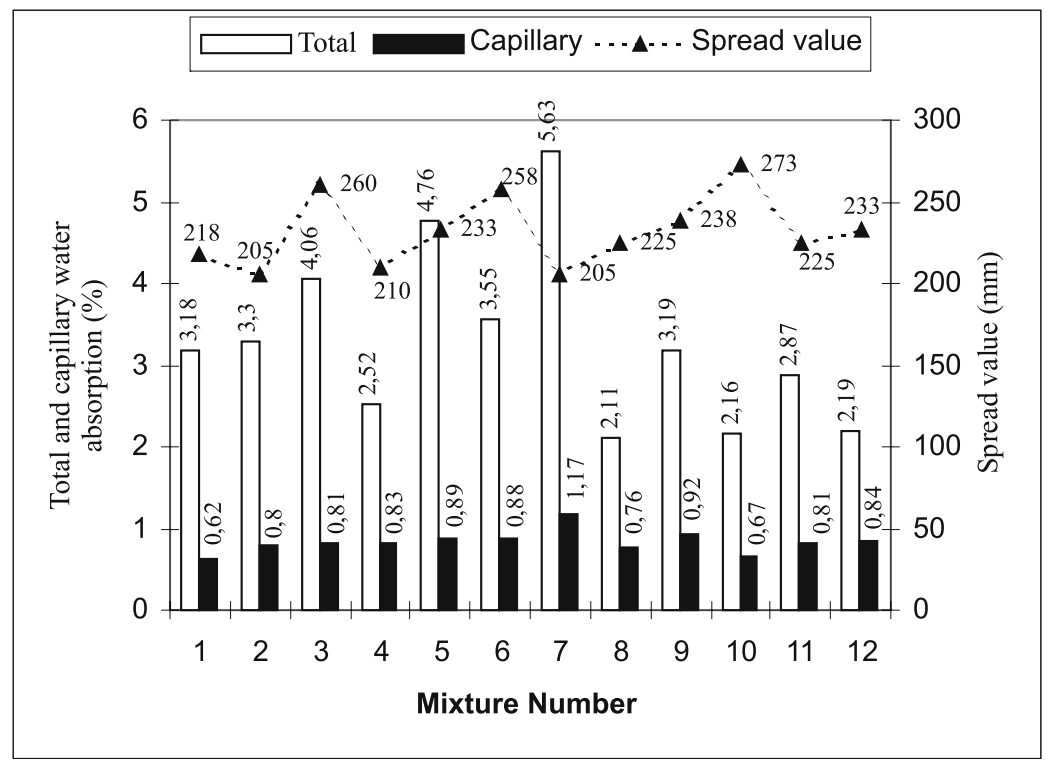

Figure 7. The total and capillary water absorption by mass (\%). 
(by the supplementary CSH structure and filler effect) at 28-days. Filling the voids in a packed system may improve the arrangement of particles in the system, ensuring a better contribution of the interfaced to achieve adequate prevent on of the mixture absorption (Yahia et al 2005). The better packing of the SF particles in the fresh state leading to an overall reduced porosity of the hcp after hydration. It should also be noted that if these tests were performed more than 28 -days old specimens (for instance, at 56 or 90 days), including mineral additives, might be expected effective lower water absorption than control mixture.

Change of the total and capillary water absorption at $24 \mathrm{~h}$ by spread value are also presented in figure 6. It can be seen from figure 6 that when the spread value of SCRMs decreased, both of the water absorption increased. For instance, highest water absorption has been obtained for M7 that is the minimum spread value of $205 \mathrm{~mm}$. In general, it can be possible that pore structures in SCRMs increased in case of spread value decreased.

\section{Conclusions}

Based on the test results presented in this paper, the following conclusions can be drawn:

(i) For targeted spread value, the dosages of SP used in mineral modified mortars changed with the mineral additives types and their combination in different proportions. The use of SF in SCRMs significantly increased the dosage of SP because of its extremely high surface area for the constant water/binder ratio. FA has an effective mineral admixture on fresh properties of SCRMs up to $20 \%$ as replacement ratio of cement. However, 20 to $30 \%$ FA replacement was not enough to show positive effect on fresh properties of SCRMs due to its low specific surface area. The most suitable additive type (for 30\% replacement ratio of cement) was LP at the same constant SP dosage (0.8\%) for workability (M3). However, the results of this study suggest that certain FA, SF and LP combinations can improve the workability of SCRMs, more than FA, SF and LP alone.

(ii) Maximum compressive strength was obtained for $30 \%$ SF replacement ratio of cement. The increase in strength can be attributed to the improved aggregate-matrix bond resulting from the formation of a less porous transition zone in the SF mortar. The lowest flexural and compressive strength at 28-days has been obtained when the use of high percent (30\%) LP (M3). It can be said that the performance of mechanical strength seems to be depending on the incorporation of FA, SF and LP. For a sufficient mechanical strength, the mixture combination must be including LP at low percent (5-10\%) while FA and SF using of up to $20 \%$. The results derived from compressive strength tests showed that LP was more effective than FA and SF in terms of early strength gain.

(iii) The total water absorption values for mixtures without SF are greater than that of control mixture. This result may bring out the opinion that LP and FA could not sufficiently to block capillary pores as well as SF at 28-days when they used alone. The lowest water absorption can be attributed to the improved aggregate-matrix bond resulting from the formation of a less porous transition zone in the silica fume concrete.

For further investigations, it is suggested that total water absorption test must be performed on beyond 28 days old specimens.

\section{References}

Altuntas Y 2005 The development of non-shrinkage self-levelling repair mortars. Master Thesis, The graduate school of natural and applied sciences, Dokuz Eylul University, Izmir 
ASTM C348 2002 Standard test method for flexural strength of hydraulic cement mortars, Annual book of ASTM standards

ASTM C349 2002 Standard test method for compressive strength of hydraulic-cement mortars (Using portions of prisms broken in flexure), Annual book of ASTM standards

ASTM C494 2002 Standard specifications for chemical admixtures for concrete. Annual book of ASTM standards

ASTM C618 2002 Standard specification for coal fly ash and raw or calcined natural pozzolan for use as a mineral admixture for concrete. Annual book of ASTM standards

Courard L A, Darimont X, Willem C, Geers R 2002 Repairing concretes with self-compacting concrete: testing methodology assessment. Proceedings of the First North American Conference on the Design and Use of Self-Consolidating Concrete, 267-274

Daimon M, Sakai E 1998 Limestone powder concerning reaction and rheology. 4th CANMET/ACI/JCI Int. Conf. on Recent Advances in Concrete Technology, Shigeyoshi Nagataki Symposium, Tokushima, Japan, 41-54

Domone P J, J Jin 1999 Properties of Mortar for Self-Compacting Concrete. Proceedings of First International Rilem Symposium on Self-Compacting Concrete. (SARL, Stockholm: RILEM Publications) $109-120$

EFNARC 2005 The European guidelines for self-compacting concrete specification, production and use. The European Federation of specialist construction chemicals and concrete systems, 63

Erdoğan T Y 1997 Admixtures for concrete, first ed., The Middle East Technical University Press, Ankara

Felekoğlu B, Türkel S, Baradan B 2004 The effect of powder type on the fresh and mechanical properties of self-compacting concrete. Turkish Ready Mixed Concrete Association, 67-77, (in Turkish)

Fujiwara H, Nagataki S, Otsuki N, Endo H 1996 Study on reducing unit powder content on highfluidity concrete by controlling powder particle size distribution. Transl. Proc. Jpn. Soc. Civ. Eng. 30(532): $117-127$

Gudmudsson G, Olafsson H 1996 Silica Fume in concrete-16 years of experience in iceland, alkaliaggregate reaction in concrete. In: A Shayan (ed.) Proceedings of the 10th International Conference, Melbourne, 462-69

Gürol G 1999 Components for Economic Concrete, cement/water/fine and coarse aggregate/chemical and mineral admixtures. J. Des. Constr. 164: 66-74 (in Turkish)

Kasselouri V, Parissakis G 1977 Stabilization of magnesia cements by adding flying ashes and slag. Silicate Indust 1: 13-17

Khayat K H 1999 Workability, testing, and performance of self-consolidating concrete. ACI Mater. J. 96(3): 346-353

Khayat K H, Morin R 2002 Performance of self-consolidating concrete used to repair parapet wall in montreal. Proceedings of the First North American Conference on the Design and Use of SelfConsolidating Concrete, 475-481

Lagerblad B, Utkin P 1993 Silica granulates in concrete-dispersion ad durability aspects. CBI Report 3.93. Swedish Cement and Concrete Research Institute, 44

Marusin S L, Shotwell L B 1995 Alkali-Silica reaction in concrete caused by densified silica fume lumps-a case study in: Proceedings of the Fifth CANMET/ACI International Conference on Fly Ash, Silica Fume, Slag and Natural Pozzolans in Concrete, Supplementary Volume, Milwaukee, $45-59$

Nawa T, Izumi T, Edamatsu Y 1998 State-of-the-art report on materials and design of self-compacting concrete. Proceedings of the Int. Workshop on Self-Compacting Concrete, 23-26 August, Kochi, Japan, 160-190

Nehdi M, Mindess S, Aitcin P C 1998 Rheology of high-performance concrete: effect of ultrafine particles. Cem. Concr. Res. 28(5): 687-697

O'Flaherty F J, Mangat P S 1999 Influence of constituents on the properties of self-compacting repair materials. In: A Skarendahl and Ö Petersson (ed.) Proceedings of the First International RILEM Symposium, 263-274 
Ozawa K, Sakata N, Okamura H 1995 Evaluation of self-compactability of fresh concrete using the funnel test. Proc. Jpn. Soc. Civ. Eng. 25: 59-75

Poston R W, Kesner K, McDonald J E, Vaysburd A M, Emmons P H 2001 Concrete repair material performance-Laboratory study. ACI Materials J. 98(2): 137-147

Shannag M J 2000 High strength concrete containing natural pozzolan and silica fume. Cement and Concrete Composites 22: 399-406

Swamy R N 1986 Concrete Technology and Design Vol. 3. Cement replacement materials. Surrey University Press

TS EN 197-1 2002 Turkish standard for cement-part 1: compositions and conformity criteria for common cements

TS 4045 1984. Turkish standard for Determination of the capillary water absorption of building materials, Ankara

Türker P, Yeşilkaya A, YeğinobalıA 2004 The hydration process and microstructural development of limestone Portland cements. Cem. Concr. World 48(8): 50-66

Villain G, Barogel-Bouny V, Kounkou C 1999 Comparative study on the induced hydration, drying and deformations of self-compacting and ordinary mortars. Proceedings of the First International RILEM Symposium, 131-142

Yahia A, Tanimura M, Shimabukuro A, Shimoyama H 1999 Effect of limestone powder on rheological behaviour of highly flowable mortar. Proc. Jpn. Concr. Inst. 21(2): 559-564

Yahia A, Tanimura M, Shimoyama Y 2005 Rheological properties of highly flowable mortar containing limestone filler-effect of powder content and W/C ratio. Cement and Concrete Res. 35: 532-539 